\title{
AÇÕES AFIRMATIVAS COMO GARANTIA E DIREITO À EDUCAÇÃO DA POPULAÇÃO NEGRA NO BRASIL
}

\author{
AFFIRMATIVE ACTIONS AS GUARANTEE AND RIGHT TO \\ THE EDUCATION OF THE BLACK POPULATION IN BRAZIL
}

\section{ACCIONES AFIRMATIVAS COMO GARANTÍA Y DERECHO A LA EDUCACIÓN DE LA POBLACIÓN NEGRA EN BRASIL}

\author{
Ronan da Silva Parreira Gaia \\ https://orcid.org/0000-0003-2342-0019 \\ Alice da Silva Vitória \\ http://orcid.org/0000-0003-4341-138X \\ João Aparecido Gonçalves Pereira \\ http://orcid.org/0000-0002-9954-0642 \\ Fabio Scorsolini-Comin \\ http://orcid.org/0000-0001-6281-3371
}

\footnotetext{
${ }^{1}$ Universidade de São Paulo, Ribeirão Preto, São Paulo - Brasil. E-mail: ronangaia@yahoo.com.br.

2 Universidade Federal de Viçosa, Rio de Janeiro, Rio de Janeiro - Brasil. E-mail: liliasv@hotmail.com.

${ }^{3}$ Universidade Federal de Goiás, Goiânia, Goiás - Brasil. E-mail: joaocidinho@ hotmail.com.

${ }^{4}$ Universidade de São Paulo, Ribeirão Preto, São Paulo - Brasil. E-mail: fabio.scorsolini@ usp.br.
}

\section{Resumo}

Análises acerca da história do Brasil evidenciam impasses aos direitos da população negra mesmo após a abolição da escravatura. A educação, direito fundamental de todo cidadão, é um dos exemplos nítidos dessa questão, e os dados estatísticos apontados ao longo do estudo comprovam a licitude desta afirmação. Assim, o presente estudo, de caráter teórico, buscou estabelecer um panorama geral, e devidamente atualizado, sobre as Políticas de Ação Afirmativa à Educação - direito fundamental - do negro no Brasil. A partir dos dados expostos neste ensaio crítico, é possível concluir que a igualdade social - garantia constitucional - só será possível quando houver a conscientização de que educação de qualidade não é mera oportunidade ou privilégio. As cotas compõem um direito fundamental aos negros e aos indígenas brasileiros não apenas devido à dívida histórica do Estado para com essas populações, mas porque o acesso à educação não deve ser apenas uma oportunidade ou fruto de uma meritocracia, e, sim, um direito do cidadão e dever do Estado. 
GAIA, R da S.P.; VITÓRIA, A. da S.; PEREIRA, J. A. G.; SCORSOLINI-COMIN, F.

Enquanto houver a deturpação de direitos civis como a educação a uma parcela específica da sociedade, a democracia neste país há de ser interrogada.

Palavras-chave: Ações Afirmativas. Direitos Fundamentais. Racismo. Educação.

\begin{abstract}
Reviews of the history of Brazil shows impasses to the rights of the black population even after the abolition of slavery. The education, fundamental right of every citizen, is one of the clear examples of this issue and the statistical data pointed out throughout the study prove the legality of this statement. Thus, the present study sought to establish an overview, duly updated, about the Affirmative Action Policies for Education - fundamental right - of black people in Brazil. From the data exposed in this critical essay, it is possible to conclude that social equality - constitutional guarantee - will only be possible when there is the awareness that quality education is not mere opportunity or privilege. Quotas make up a fundamental right for blacks and indigenous brazilians not only because of the State's historic debt to these populations, but because access to education should not be just an opportunity or the result of a meritocracy, but a citizen's right and duty of the State. As long as there is a misrepresentation of civil rights such as education for a specific part of society, democracy in that country must be questioned.
\end{abstract}

Key words: Affirmative Actions. Fundamental Rights. Racism. Education.

\title{
Resumen
}

Los análisis sobre la historia de Brasil muestran obstáculos a los derechos de la población negra incluso después de la abolición de la esclavitud. La educación, derecho fundamental de cada ciudadano, es uno de los ejemplos claros de este tema y los datos estadísticos señalados a lo largo del estudio prueban la legalidad de esta declaración. Por lo tanto, el presente estudio buscó establecer una visión general y debidamente actualizada de las Políticas de Acción Afirmativa en Educación - derecho fundamental - de los negros en Brasil. Desde los datos expuestos en este ensayo crítico, es posible concluir que la igualdad social - garantía constitucional - solo será posible cuando exista la conciencia de que la educación de calidad no es simplemente una oportunidad o un privilegio. Las cuotas constituyen un derecho fundamental para los negros y los brasileños indígenas no solo por la deuda histórica del Estado con esas poblaciones, sino porque el acceso a la educación no debe ser solamente una oportunidad o el resultado de una meritocracia, sino un derecho ciudadano y deber del Estado. Mientras haya una tergiversación de los derechos civiles como la educación para una parte específica de la sociedad, la democracia en este país debe ser cuestionada.

Palabras clave: Acciones Afirmativas. Derechos Fundamentales. Racismo. Educación.

\section{Introdução}

Após séculos calcados em um regime de escravidão racializada e sobre um projeto de nação elaborado por uma lógica eugenista (BOLSANELLO, 1996), também perfilada por sucessivos regimes autoritários, o Brasil assumiu, em 1988, uma Carta Magna coerente com a 
Declaração Universal dos Direitos Humanos, de 1948, com a afirmação de uma democracia e com um teor mais inclusivo. Também nessa data marcaram-se100 anos da abolição da escravatura no país, e a população negra teve sua voz ouvida, de maneira inédita, na elaboração de políticas que lhe diziam respeito. Dessa vez o debate, diferente do contexto da abolição (AZEVEDO, 1989), teve as pautas do Movimento Negro na construção da Constituição, inclusive criminalizando o racismo com a aprovação - em 2 de fevereiro de 1988 - da emenda aditiva ao projeto de Constituição de autoria do, na época deputado federal, Carlos Alberto Caó ${ }^{1}$, também proponente da Lei n. 7.716/89² (BRASIL, 1989).

Essas colaborações, todavia, infelizmente não foram levadas a contento no âmbito prático, pois restringiu-se aos papéis na ausência de iniciativas que cumprissem de fato as políticas públicas de inclusão do negro na sociedade (SANTOS, 2015). A priori, como o problema do racismo era desconsiderado, as poucas práticas estatais em torno do assunto também não poderiam ser eficazes. A partir do reconhecimento do problema do racismo no Brasil, o desenvolvimento dos direitos dos negros continua barrado pela mesma lógica racista, porém não simplesmente por meio do desdém governamental, e, sim, por uma máquina estatal ineficaz em um país ex-colônia de exploração regido por uma oligarquia burocrática.

Ao discorrer acerca da relação entre opressores e oprimidos, Paulo Freire considera que “(...) para eles [os opressores], pessoa humana são apenas eles. Os outros, estes são 'coisas' (...)” (1987, p. 45). É fato que Freire não escrevia acerca do racismo, mas da opressão de maneira geral, sobretudo a que atravessava os processos educacionais e de acesso à educação por parte de toda a população. O racismo, no entanto, é uma forma de opressão racial extremamente sofisticada, estruturada (ALMEIDA, 2018) e, muitas vezes, camuflada, que também atravessa as relações com o sistema educacional, principalmente no Brasil, onde, apesar de todo o contexto histórico, o racismo pode ser considerado uma "brincadeira", piada de mau gosto, equívoco, sem a intenção de causar ofensas (DAHIA, 2010). Assim, observa-se um apagamento do racismo, criando-se uma ilusão de o Brasil como um país sem preconceitos e, mais complexo ainda, no qual não existiria o racismo.

Voltando à obra de Paulo Freire, vale destacar a influência do psiquiatra Frantz Fanon (2005), haja vista que se tratam de estudiosos contemporâneos entre si. Fanon (2005) salienta que a história é contada a partir da perspectiva do colonizador, branco, de modo que ao

\footnotetext{
${ }^{1}$ Autor do inciso XLII do artigo $5^{\circ}$ da Constituição Federal de 1988.

${ }^{2}$ Popularmente conhecida como "Lei Caó".
} 
GAIA, R da S.P.; VITÓRIA, A. da S.; PEREIRA, J. A. G.; SCORSOLINI-COMIN, F.

colonizado, o negro, é relegado um lugar de apagamento, de opressão, na medida em que a ele não é oferecida a oportunidade de escrever a sua história, sob sua perspectiva. Esse processo promoveria grande sofrimento na população negra também pelo fato de não poder se identificar com o seu povo colonizado. O colonizador, branco, emerge como personagem que passa a ser perseguido pelo negro como um ideal, promovendo o desejo, muitas vezes, de se embranquecer para corresponder aos anseios que circulam no espaço discursivo que narra a vitória do colonizador e a opressão do colonizado. Assim, não seria possível ao negro identificar-se com o próprio negro, uma vez que ele seria o colonizado, o oprimido, o submetido ao jugo branco civilizatório como se, este sim, fosse o herói. Esse processo cravarse-ia profundamente na identidade do negro e também no modo como a sua história passaria a ser contada - por negros, pelos negros e para os negros.

O que tanto o pensamento de Fanon (2005) como o de Freire (1987) pontuam é que essa lógica do opressor/colonizador estaria presente em toda a sociedade, de modo que a educação passaria a ser pensada também por meio dessa estrutura. Assim, o espaço do narrador seria exclusivamente euro-americano, o que atravessaria, inclusive, a história da população negra no Brasil em sentidos como, por exemplo, o da abolição da escravatura como um movimento de um branco benevolente e ciente das assimetrias impostas por uma sociedade escravagista. Ao se estabelecer essa narrativa, opera-se justamente todo o movimento negro de resistência e a abolição passa a ser um feito heroico do opressor em direção ao oprimido.

Esse exemplo clássico assinala a construção de uma narrativa histórica fortemente presente nas escolas, promovendo que esses espaços de educação formal estejam alinhados não à desconstrução de saberes arraigados e porosos à retórica branca e opressora, mas à perpetuação de assimetrias e de reforço de narrativas que não são condizentes com a história. Juremir Machado da Silva, em Raízes do Conservadorismo Brasileiro (2018), afirma que a riqueza do Brasil foi construída pelos negros africanos em um processo permeado por extrema violência. A mancha promovida por séculos de escravidão ainda se encontra corporificada em nossa sociedade.

A hegemonia dos ditos "vencedores inescrupulosos" (SILVA, 2018, p. 11) estruturou, por muito tempo, a cultura e a sociedade brasileiras sobre inverdades acerca da constituição do país, inclusive sob a chancela de instituições de ensino formal-escolar (FONSECA; BARROS, 2006). Mesmo que abdicada cientificamente, hoje observamos, com certa 
frequência, nos discursos dos sujeitos que se autodeclaram "não racistas", a defesa de que o racismo não existe no Brasil, a ideia de que só há uma única raça, a humana, e que o brasileiro é fruto da miscigenação, portanto, não havendo critério racial para classificá-lo (TORRES, 2012). Mais do que isso, essa miscigenação é revelada midiaticamente como uma das principais características do nosso povo, responsável pela sua flexibilidade e pelo seu caráter eminentemente pacificador e acolhedor. Ao se defender uma identidade mestiça associada ao brasileiro, opera-se justamente o apagamento de suas heranças. A narrativa negra de nossa história, portanto, teria se esvanecido ao mesclar-se com a retórica emergente da miscigenação como traço de um povo.

Esses atos são reproduções de atitudes racistas, pois ambas as falas apontadas anteriormente buscam, inconsciente ou hipocritamente, e nesse caso pelo racismo, apagar "o mais hediondo crime contra a humanidade" (SILVA, 2018, p. 11), ou seja, a escravidão, como se suas consequências não se perpetuassem na atualidade (TORRES, 2012). Essa concepção concede ao sujeito branco o aval necessário para se colocar como inocente quando o assunto é racismo, eximindo-se do seu compromisso histórico para com esse tema e, sobretudo, para com a população negra. As relações raciais no Brasil são demasiadamente complexas e carregam ainda a lógica do "preconceito de não ter preconceito" (BASTIDE; FERNANDES, 1955), que transforma uma denúncia de racismo em um insulto ou injúria racial, muitas vezes vistos como mais graves que a própria atitude racista. Assim, a vítima de racismo passa a ser revitimizada, eximindo seu opressor de qualquer sanção.

Em face do exposto, o objetivo do presente estudo é apresentar, a partir de argumentos jurídicos, históricos e sociais, as ações afirmativas quanto ao direito fundamental do negro que atravessou negligências múltiplas no contexto brasileiro. Há uma dívida histórica do Brasil para com esse grupo social, razão que por si só serve[ria] para justificar a costura do presente ensaio. É importante tratar desse tema, mantê-lo em discussão devido à negação histórica à educação aos negros no país, as quais se deram pelos diversos fatores que serão apontados a seguir e que, inequivocamente, corporificam-se no modo como essa população pode acessar o seu constitucional direito à educação. 


\section{Aspectos jurídicos e sociais}

Os dados trazidos pelo Censo do Instituto Brasileiro de Geografia e Estatística (IBGE, 2010) mostram que a maioria da população brasileira é negra, ${ }^{3}$ sendo que 14.517 .961 pessoas se declaram pretas e 82.277.333 se declaram pardas. Pesquisas como essa são recentes no país, conhecido por ser multiétnico-cultural. Foram poucos os momentos em que foi interessante estabelecer um censo racial na história do país.

Para os dados de 1872, a intenção era saber quão distante da civilização, associada ao homem branco, o Brasil se enquadrava. O projeto de nação brasileira buscava embranquecer o país a todo custo e, para tal, era necessária a extinção das populações não brancas (BOLSANELLO, 1996; JACCOUD, 2008). A grande questão que se colocava entre os intelectuais da época era se esse genocídio seria por meio da miscigenação, na qual, como acreditavam os cientistas da época, supostamente iria prevalecer a raça branca. De toda forma, contavam ainda com o auxílio de políticas públicas assistencialistas que favoreciam os lidos socialmente como brancos, como o incentivo à imigração de famílias de países europeus.

Em se tratando da miscigenação, vale destacar que essa ideia tinha como pano de fundo a concepção de purificação racial da população brasileira, e isso consistiria no progresso da nação e na criação de uma democracia racial. Ao comentar sobre esse assunto, Araújo (2006, p. 76) afirma que, no Brasil, a "miscigenação esteve sempre associada à ideia de que nesta terra se criava uma nação com uma nova raça, os brasileiros, frutos de um hibridismo em que prevaleceria a homogeneidade racial e cultural". O autor ainda chama atenção para o fato de que a miscigenação "foi um traço comum na construção da identidade nacional da maior parte dos países latino-americanos". Por conseguinte, onde houve esse tipo de construção, "a existência de negros e índios foi progressivamente apagada ou, no mínimo, diluída a partir da apropriação das suas culturas como parte integrante de uma nova cultura nacional original" (ARAÚJO, 2006, p. 76). As raízes históricas de nosso povo passavam a ser, nesse contexto, negadas e igualmente apagadas, permitindo o acesso a um discurso histórico oficial que figurava o branco como herói benevolente e a miscigenação como traço de uma brasilidade que poderia progredir indiferente às suas dívidas históricas.

No contexto de formação da república brasileira, pós-abolição e segregação política, cultural e social dos negros, estes encontram-se majoritariamente sob condição de pobreza e

\footnotetext{
${ }^{3}$ Utilizaremos essa terminologia para definir pretos e pardos, como dispõe o inciso IV do Estatuto de Igualdade Racial - Lei n. 12.288/2010 (BRASIL, 2010).
} 
aglomeram-se nas periferias (em todos os sentidos possíveis) das grandes cidades, as ditas favelas (SANTOS, 1994). Sempre articulando maneiras de sobrevivência em diáspora, a população negra brasileira vem sobrevivendo a todos os obstáculos que têm sido postos desde os tempos de senzala. Vítimas também do que podemos classificar como racismo ambiental, os direitos que deveriam ser garantidos pelo Estado também sofrem com o descaso de um país calcado em desigualdades e que, portanto, legitima essas assimetrias, abrindo brechas para as atuais discussões acerca da meritocracia no acesso à educação formal, por exemplo.

Os dados do Ministério da Justiça e Segurança Pública (BRASIL, 2019) destacam em que espaço a forte presença da população negra parece ser bem-vinda, visto que a "hierarquia racial reforça os diferentes lugares na sociedade" (JACCOUD, 2008, p. 61). Jovens negros são maioria nos quadros estatísticos entre os privados de liberdade em todos os estados do país (BRASIL, 2019), e é inviável analisar esses dados sem considerar o passado escravista do país que, por sinal, consolidou o sistema jurídico brasileiro. Devido a isso, autores assinalam que foi desenvolvido um direito penal essencialmente racista e, portanto, de acordo com o projeto de nação, com a estrutura societária do país e válido para o genocídio da população negra no Brasil (NASCIMENTO, 2016).

Durante o período escravocrata, mesmo as leis pensadas para resolver questões sobre os negros não os favoreciam. As icônicas leis do Ventre Livre e do Sexagenário não passaram de novos problemas a serem encarados pelos negros (RAMOS, 2012), mas são muitas vezes apresentadas durante a escolarização formal como inovações. Assim como muitas práticas estatais no país, o objetivo final era permitir a prevalência do racismo, agente motor do desenvolvimento no Brasil desde os tempos da colônia.

Um bom exemplo é a perpetuação, até os dias de hoje, da legislação imperial que permitia acesso à educação pública aos nascidos no Brasil (FONSECA; BARROS, 2006; SOUSA, 2005), exceto escravos, desconsiderando também o contexto vivido pela população negra alforriada em que estudar não era uma prioridade. Agora, esse preterimento da educação é visto em uma cultura construída no favorecimento de necessidades básicas e urgentes. Mesmo que haja a possibilidade de acessar as instituições públicas de ensino, há uma realidade muito mais complexa, e que não pode ser ignorada, que limita essa oportunidade a um privilégio.

Sob o manto do mito da democracia racial (NASCIMENTO, 2016), as desigualdades nos índices de escolaridade no Brasil são postas como um problema de classe social, e não 
GAIA, R da S.P.; VITÓRIA, A. da S.; PEREIRA, J. A. G.; SCORSOLINI-COMIN, F.

como um problema que afeta uma etnia que foi, e continua sendo, segregada e excluída daquilo lhe deveria ser acessível. O país conta com 7,2\% de pessoas sem instrução e menos de um ano de estudo, 36,2\% que não concluíram o ensino fundamental e 6,8\% que não concluíram o ensino médio (IBGE, 2019). Vale indicar, ainda, que a taxa de analfabetismo entre brancos é de 4,2\%, enquanto entre pretos ou pardos é de 9,9\%, segundo dados da Pesquisa Nacional por Amostra de Domicílios (PNAD) de 2016 (GOMES; MARLI, 2018). Os jovens negros veem no acesso às universidades uma distância física, cultural e estrutural, o que foi criado ao longo da história como mais uma das sequelas da escravidão: o racismo estrutural (ALMEIDA, 2018).

O racismo ambiental se assenta no fato de as universidades não se instalarem em bairros periféricos, em sua maioria, dificultando o acesso da população negra a esse espaço, tanto para a educação formal como para o acesso, por exemplo, a serviços extensionistas voltados à comunidade. Já as instituições de educação básica instaladas nesses bairros são, muitas vezes, tão deficitárias quanto seus componentes (SANTOS, 1994). O racismo estrutural (ALMEIDA, 2018) permite a distância estrutural. E ambos concedem uma socialização que apartem culturalmente o negro do universo acadêmico.

Todas essas ações possuíam o aval legal das Constituições Federais até 1988. O caráter da nova Constituição Federal fez que, a partir desse novo período democrático, fosse possível a constitucionalização das cotas como política de ações afirmativas para negros e indígenas no país (BRASIL, 2012). Elas não somente legitimam os direitos conquistados pela população negra, como também deslegitimam todas as demais ações realizadas pelo Estado antes dela, ações essas que apenas foram possíveis devido ao não reconhecimento legal do país como uma nação racista. Toda a ideia de miscigenação (TORRES, 2012) usada para argumentar contra essa verdade precisou ser revisitada, o que inevitavelmente apontou para as reais intenções de origens eugenistas do nascimento do país (JACCOUD, 2008).

\section{Ações Afirmativas e Educação à Luz da Inclusão Étnico-racial}

Em 2012, ano em que João Baptista de Lacerda havia previsto o embranquecimento integral do Brasil (LACERDA, 1911; NASCIMENTO, 2016), o Supremo Tribunal Federal (STF) constitucionalizou as cotas como política de ação afirmativa para negros e indígenas após discussão da Arguição de Descumprimento de Preceito Fundamental (ADPF) 186 
(BRASIL, 2012). O país, ou melhor, a elite, que antes angustiava-se pelo demasiado tempo que previam os cientistas para seu embranquecimento, ou seja, para sua "civilização" (NASCIMENTO, 2016), hoje discute, não sem ressalvas e fortes resistências, a dívida histórica que tem para com os negros. Trata-se de fazer valer o princípio constitucional da isonomia, cujo melhor exemplo no momento é a política de cotas de ações afirmativas.

Para definir ações afirmativas nos respaldamos nos termos do artigo 1, inciso VI, do Estatuto de Igualdade Racial - Lei n. 12.288/2010, que as concebem como todos "os programas e medidas especiais adotados pelo Estado e pela iniciativa privada para a correção das desigualdades raciais e para a promoção da igualdade de oportunidades” (BRASIL, 2010). Trata-se de iniciativas em prol da afirmação de uma população que foi historicamente negada e que internalizaram em si, pela socialização de uma sociedade excludente e por meio da educação, um auto-ódio gerado por um ideal de ego ferido que resulta no processo de denegação (GONZALES, 1988). As cotas, que por tantos anos beneficiaram brancos no Brasil (SANTOS, 2015a), servem não apenas para incluir, mas também para incentivar o negro a autoafirmar sua identidade, trabalhando o empoderamento dos sujeitos afrodescendentes.

É necessário desconstruir o mito da democracia racial, o qual enseja a criação de estereótipos acerca das políticas de cotas raciais. Tal mito impede o reconhecimento da necessidade de promover a inclusão do negro na sociedade a partir de políticas públicas afirmativas como as cotas raciais. Outros movimentos podem ser assinalados nesse contexto, como a tentativa de deslegitimar a população beneficiária dessas ações. Estudos acerca das cotas raciais nas universidades, por exemplo, colocam-se a investigar as possíveis (e hipotéticas) assimetrias entre brancos e alunos que ingressaram por conta das ações afirmativas (QUEIROZ; MIRANDA; TAVARES; FREITAS, 2015). Ainda que as conclusões da maioria dessas investigações não ofereçam suporte para uma pretensa afirmação de assimetria em termos de desempenho, conjectura-se que esse movimento operado na pesquisa possa ser disparador de um pensamento que, para além de compreender a corporificação das ações afirmativas, amplie o preconceito e até mesmo a perseguição aos alunos ditos cotistas.

A partir de uma égide que defende a avaliação desses programas de acesso ao ensino superior público, a mesma opera-se por uma lógica que visa a segregar, e não a diminuir, as possíveis distâncias de oportunidades e de conhecimentos entre esses alunos. Os possíveis resultados desses estudos, portanto, nem sempre estão comprometidos com uma lógica que objetiva aperfeiçoar a política das cotas e, sobretudo a sua implementação também dentro da 
GAIA, R da S.P.; VITÓRIA, A. da S.; PEREIRA, J. A. G.; SCORSOLINI-COMIN, F.

universidade, em termos de acolhimento institucional, mas munir as críticas que assinalam a ineficiência dessas políticas. Assim, busca-se reforçar o preconceito existente em relação à população afrodescendente - o que se expande para as cotas de acesso ao ensino superior público -, como se a universidade fosse, de fato, um lugar interdito ao negro.

Ao se buscar a comparação entre os chamados cotistas e não cotistas, centra-se na cognição do aluno e em seu desempenho acadêmico a responsabilidade por manter a necessidade das cotas, em vez de se explorar, de fato, o passado e seus processos históricos que culminaram na necessidade das ações afirmativas, bem como o ensino básico que possibilita o acesso ao ensino superior em nosso país. A maioria desses estudos, no entanto, tem assinalado que não há significativas diferenças entre esses alunos e que as possíveis disparidades tendem a diminuir significativamente ao longo do curso (QUEIROZ et al., 2015), o que nos autoriza a considerar que a universidade tem um papel importante no sentido de permitir, de fato, a construção de um espaço mais igualitário em oportunidades, podendo dar uma resposta concreta à chamada dívida histórica na qual se sustenta a maior parte das ações afirmativas, entre elas as de acesso ao ensino superior.

Vale mencionar o modo como o ensino de história privilegia interesses brancos, oligárquicos (ALBUQUERQUE JÚNIOR, 2012) e propaga mitos fundadores como o da democracia racial. Nesse ponto, a educação é da melhor qualidade, diferentemente do que apresentam os últimos dados sobre o assunto no país (FUNDAÇÃO TELEFÔNICA BRASIL, 2018). Se esse específico ensino de história não tivesse êxito, não haveria tantas polêmicas acerca das ações afirmativas, pois todos os sujeitos seriam conscientes da dívida histórica que o Brasil tem com a população negra e a lógica pejorativa sobre as cotas (TORRES 2012) não ganharia tamanho espaço. Aventa-se que o desconhecimento sobre o real passado do nosso país é que gera tantas polêmicas sobre esse assunto. Trata-se, portanto, de pontuar que esse desconhecimento se refere, sobretudo, à história dos negros no Brasil. Esse desconhecimento enseja a criação de estereótipos sobre as cotas raciais e outras políticas afirmativas voltadas para os afrodescendentes.

A partir do argumento central deste estudo, deve-se destacar a necessidade de a educação estar alinhada a um paradigma que, de fato, reassegure a posição e a relevância das ações afirmativas. Para auxiliar nesse processo, é mister que os espaços educacionais possam estar não apenas comprometidos com a discussão acerca dessas ações afirmativas, mas reassegurando que a educação seja capaz de tocar essa questão com o compromisso 
necessário ao amadurecimento do tema e sua real incorporação à agenda política e institucional em nosso país.

Por tudo isso é preciso problematizar a educação dada à maioria dos negros no país, vítimas, nesses casos, do epistemicídio (CARNEIRO, 2005). O epistemicídio promove, como um de seus efeitos, a negação, aos negros, de acesso à posição de sujeitos do conhecimento, ocultando, por exemplo, as inequívocas contribuições do continente africano à humanidade. Assim, é mister repensar a educação dada a todos em nosso país acerca da história do negro, da África e da escravidão em nosso país, por exemplo. A Lei n. 10.639/03 ${ }^{4}$ procura sanar esse problema incluindo nas escolas e universidades uma visão ampla da história, a qual não pode ser unicamente eurocentrada (BRASIL, 2003). Há questionamentos sobre a implementação dessa lei nas instituições de ensino do país, entre eles o de, se esse movimento partir de um modelo euro-americano, possivelmente as assimetrias tenderão a se manter, assim como a invisibilidade de algumas questões. Assim, a mera incorporação do tema aos espaços formais de educação não pode garantir que essa história seja recontada. Há que se problematizar que, de fato, essa história possa ser recontada por seus sujeitos, em uma perspectiva afrocentrada que, de fato, resgate a ancestralidade que tem marcado essa questão e que justamente tem sido negada não só no ensino de história, mas também no modo como a universidade ainda se mantém distante dessa seara. É preciso, portanto, que essa incorporação parta de um argumento distinto: revisitar essa história sob o prisma do colonizado, a partir do qual se pode aventar a adoção de uma narrativa que, de fato, combata o racismo, a opressão e a desigualdade.

$\mathrm{O}$ assunto, todavia, mostra-se mais profundo se enfatizarmos a contradição entre a conquista das cotas de ações afirmativas e a continuidade do processo de genocídio dos povos negro e indígena denunciado por Abdias do Nascimento nos anos 1970 e recorrente pauta dos movimentos negros atuais. Se a intenção eugenista do Estado persistir, que conteúdo será ensinado a esses estudantes negros que agora ocupam cadeiras nas grandes universidades públicas do país? Além disso, há de se pensarem os limites do racismo institucional ao se possibilitarem pesquisas interessantes e iniciadas por esse grupo social. Se problematizarmos, por exemplo, a quantidade de professores negros no ensino superior, talvez tenhamos uma dimensão da possibilidade de essa história, de fato, ser recontada, e não apenas contada novamente. Segundo levantamento publicado pela Universidade de São Paulo em seu Portal

\footnotetext{
${ }^{4}$ Que altera a Lei de Diretrizes e Bases da Educação Nacional (LDBEN), incluindo no currículo oficial da educação básica a obrigatoriedade da temática "História e Cultura Afro-Brasileira".
} 
GAIA, R da S.P.; VITÓRIA, A. da S.; PEREIRA, J. A. G.; SCORSOLINI-COMIN, F.

da Transparência (2019), apenas 2,1\% de seus mais de 5.000 professores são pretos ou pardos.

Para solucionar tais questões, professores e intelectuais negros brasileiros possuem a ferramenta das Leis 10.639/03 e 11.645/08 (BRASIL, 2003; BRASIL, 2008); todavia é necessário pontuar que é crucial que essas leis ajam junto às cotas, compondo, entre outros dispositivos ${ }^{6}$, as Políticas de Ações Afirmativas sob a chancela da Política Nacional de Promoção à Igualdade Racial (BRASIL, 2003). Esta exposição pretende apontar para o fato de que, sem a garantia de uma educação não epistemicida, as ações afirmativas foram (e continuam sendo) importantes prerrogativas de acesso à inclusão do negro e à redução das desigualdades - principalmente no âmbito da educação pública superior. Ainda são insuficientes, contudo, para contribuir para a inclusão social do negro em uma educação de qualidade, seja ela básica ou superior (principalmente as instituições públicas de ensino superior $^{7}$, pois ele precisa entender-se enquanto sujeito, cidadão de direitos, parte da sociedade e parte da história, tendo seus feitos valorizados e representados. Afinal, como inicia a segunda citação desse texto, o Brasil foi feito pela mão do negro (SILVA, 2018), e essa contribuição precisa ser reconhecida não somente por aqueles que gozam das heranças (tanto socioculturais como financeiras) dos grandes engenhos, mas principalmente por todos e todas os negros e negras brasileiros.

\section{Considerações finais}

Diante dos argumentos sumarizados no presente artigo, conclui-se que somente ocorrerá uma inclusão social do negro no Brasil, de fato, quando as cotas não forem mais necessárias e a educação não for epistemicida. Em um quadro sem a necessidade da política de cotas de ações afirmativas, a tarefa da inclusão já estará completa e, concomitantemente, será valorizada toda a diversidade de saberes contidos no Brasil. Isso significa que prezar em educar um ideal de homem brasileiro, referenciado no homem branco europeu, não deve ser mais o objetivo final da escolarização neste país, que caminha para um currículo escolar que

\footnotetext{
${ }^{5}$ Que altera a Lei de Diretrizes e Bases da Educação Nacional (LDBEN), incluindo no currículo oficial da educação básica a obrigatoriedade da temática "História e Cultura Afro-Brasileira e Indígena".

${ }^{6}$ Podendo ser citadas as Diretrizes Curriculares Nacionais para a Educação das Relações Étnico-Raciais e para o Ensino da História Afro-Brasileira e Africana (BRASIL, 2004), a Lei n. 12.990, de 9 de junho de 2014, por exemplo.

${ }^{7}$ Antes restrita de modo quase exclusivo aos mais abastados e à classe média - ambos em sua maioria brancos que se preparavam em escolas privadas de ponta (SANTOS, 2015a).
} 
dê o devido direito à voz aos não brancos, classe como um todo ignorada pelo padrão educacional até então. Vale lembrar que todas as considerações aqui postas sobre a população negra no Brasil também cabem às populações indígenas, vítimas do mesmo mal e contempladas pelas ações afirmativas, tanto pelo direito às cotas como pela Lei n. 11.645/08, que altera a Lei de Diretrizes e Bases da Educação Nacional (LDBEN) ${ }^{8}$ (BRASIL, 2008; BRASIL, 1996).

É pertinente a revisão do termo "cota" para que seja possível a conscientização da população sobre seu papel na sociedade, tal como uma justificativa concisa para essa política pública, haja vista que o termo "cota" acabou por se tornar pejorativo na complexa imensidão dos debates sobre raça no país, o que, por consequência, reduziu o significado de uma política tão importante quanto as ações afirmativas. Trata-se, vale destacar, de uma política pública sempre presente no contexto brasileiro, na medida em que sempre houve cotas para a população considerada branca no Brasil (SANTOS, 2015a). Não apenas a inclusão social do negro mediante, entre outras ações, as cotas de ações afirmativas são urgentes e necessárias, mas a redução do que Hélio Santos (2015a) chama de cotas para brancos, isto é, os inúmeros privilégios sociais, e mesmo assistencialismos estatais históricos, precisam ser, na mesma medida, diminuídos até que haja um equilíbrio.

No mais, as cotas compõem um direito fundamental aos negros e indígenas brasileiros não apenas devido à dívida histórica do Estado para com essas populações, mas porque o acesso à educação não deve ser apenas uma oportunidade ou fruto de uma meritocracia, e, sim, um direito do cidadão e dever do Estado, como concebe a Constituição Federal de 1988 em seu artigo 205 (BRASIL, 1988). Enquanto houver a deturpação, tão eficiente, de direitos civis como a educação a uma parcela específica da sociedade, a democracia neste país há de ser interrogada.

\section{Referências}

ALBUQUERQUE JÚNIOR, D. M. Fazer defeitos nas memórias: para que servem o ensino e a escrita da história? In: GONÇALVES, M. et al. (org.). Qual o valor da história hoje? Rio de Janeiro: Editora FGV, 2012, p. 21-39.

ARAÚJO, J. Z. A força de um desejo - a persistência da branquitude como padrão estético audiovisual. Revista USP, São Paulo, n. 69, p. 72-79, 2006.

\footnotetext{
${ }^{8}$ Lei n. 9.394/96 (BRASIL, 1996).
} 
GAIA, R da S.P.; VITÓRIA, A. da S.; PEREIRA, J. A. G.; SCORSOLINI-COMIN, F.

ALMEIDA, S. L. O que é racismo estrutural? Belo Horizonte: Letramento, 2018.

AZEVEDO, C. M. M. Onda negra, medo branco: o negro no imaginário das elites - século XIX. Rio de Janeiro: Paz e Terra, 1989.

BASTIDE, R.; FERNANDES, F. Relações raciais entre negros e brancos em São Paulo. São Paulo: UNESP/Anhembi, 1955.

BOLSANELLO, M. A. Darwinismo social, eugenia e racismo "científico": sua repercussão na sociedade e na educação brasileira. Educação Revista, Curitiba, n. 12, p. 153-165, 1996.

BRASIL. Constituição da República Federativa do Brasil. Brasília, DF: Senado Federal, 1988.

BRASIL. Decreto n. 4.886, de 20 de novembro de 2003. Institui a Política Nacional de Promoção à Igualdade Racial e dá outras providências. Disponível em:

http://www.planalto.gov.br/ccivil_03/decreto/2003/D4886.htm. Acesso em: 8 jul. 2019.

BRASIL. Lei n. 7.716 de 5 de janeiro de 1989. Casa Civil. Subchefia para assuntos

jurídicos. Define os crimes resultantes de preconceito de raça ou de cor.

BRASIL. Lei n. 9.394, de 20 de dezembro de 1996. Lei de Diretrizes e Bases da Educação Nacional - LDBEN. Brasília: Casa Civil, 1996.

BRASIL. Diretrizes Curriculares Nacionais para a Educação das Relações ÉtnicoRaciais e para o Ensino da História Afro-Brasileira e Africana. Brasília: SECAD/ME, 2004.

BRASIL. Lei n. 10.639, de 9 de janeiro de 2003. Altera a lei n. 9.394, de 20 de dezembro de 1996, que estabelece as diretrizes e bases da educação nacional, para incluir no currículo oficial da rede de ensino a obrigatoriedade da temática "História e Cultura Afro-brasileira", e dá outras providências.

BRASIL. Lei n. 11.645, de 10 março de 2008. Altera a Lei no 9.394, de 20 de dezembro de 1996, modificada pela Lei no 10.639, de 9 de janeiro de 2003, que estabelece as diretrizes e bases da educação nacional, para incluir no currículo oficial da rede de ensino a obrigatoriedade da temática "História e Cultura Afro-Brasileira e Indígena".

BRASIL. Lei n. 12.288, de 20 de julho de 2010. Institui o Estatuto da Igualdade Racial. Disponível em: http://www.planalto.gov.br/ccivil_03/_ato2007-2010/2010/lei/112288.htm. Acesso em: 8 jul. 2019.

BRASIL. Lei n. 12.711, de 29 de agosto de 2012. Dispõe sobre o ingresso nas universidades federais e nas instituições federais de ensino técnico de nível médio e dá outras providências. Brasília: Casa Civil, 2012.

BRASIL. Lei n. 12.990, de 9 de junho de 2014. Reserva aos negros $20 \%$ (vinte por cento) das vagas oferecidas nos concursos públicos para provimento de cargos efetivos e empregos públicos no âmbito da administração pública federal, das autarquias, das fundações públicas, das empresas públicas e das sociedades de economia mista controladas pela União.

Disponível em: http://www.planalto.gov.br/ccivil_03/_Ato2011-2014/2014/Lei/L12990.htm. Acesso em: 6 jul. 2019.

BRASIL. Ministério da Justiça e Segurança Pública. Levantamento Nacional de

Informações Penitenciárias, atualização junho de 2017. Brasília: Ministério da Justiça e Segurança Pública, Departamento Penitenciário Nacional, 2019, 87 f. Disponível em: 
file://C:/Users/lili-/Downloads/infopen-jun-2017-rev-12072019-0721.pdf. Acesso em: 20 jul. 2019.

BRASIL. Supremo Tribunal Federal. Arguição de Descumprimento de Preceito Fundamental n. 186. Relator: Ministro Ricardo Lewandowski, Tribunal Pleno, julgado em 26/4/2012, Acórdão Eletrônico. Diário da Justiça Eletrônico, Brasília, DF, n. 205, 17 de outubro de 2014.

CARNEIRO, S. A. A construção do Outro como Não-Ser como fundamento do Ser. 2005. 339 f. Tese (Doutorado em Educação). Faculdade de Educação, Universidade de São Paulo, São Paulo.

DAHIA, S. L. M. Riso: uma solução intermediária para os racistas no Brasil. Estudos e Pesquisas em Psicologia, v. 10, n. 2, p. 373-389, 2010.

FANON, F. Os condenados da terra. 2. ed. Rio de Janeiro: Civilização Brasileira, 2005. $373 p$.

FONSECA, M. V.; BARROS, S. A. P. (org.). A História da Educação dos Negros no Brasil. Niterói: EdUFF, 2016. 442p.

FREIRE, P. Pedagogia do oprimido. 17. ed. Rio de Janeiro: Editora Paz e Terra, 1987.

FUNDAÇÃO TELEFÔNICA BRASIL. Quatro dados Alarmantes sobre a Educação

Brasileira. Publicado 04 de julho de 2018. Disponível em:

http://fundacaotelefonica.org.br/noticias/quatro-dados-alarmantes-sobre-a-educacaobrasileira/. Acesso em: 20 jul. 2019.

GOMES, I.; MARLI, M. As cores da desigualdade. Retratos - a revista do IBGE, n. 11, p. $15-25,2018$.

GONZALEZ, L. A categoria político-cultural de amefricanidade. Tempo Brasileiro, Rio de Janeiro, n. 92/93. p. 69-82, 1988.

IBGE. Censo Demográfico 2010. População residente, por cor ou raça, segundo a situação do domicílio, o sexo e a idade. Instituto Brasileiro de Geografia e Estatística - IGBE. 2010.

IBGE. População, por níveis de instrução. Pesquisa Nacional por Amostras de Domicílios Contínua trimestral. Instituto Brasileiro de Geografia e Estatística - IGBE. 2019.

JACCOUD, L. Racismo e República: o debate sobre o branqueamento e a discriminação racial no Brasil. In: THEODORO, M. (org.). As políticas públicas e a desigualdade racial no Brasil 120 anos após a abolição. Brasília: IPEA, 2008.

LACERDA, J. B. Sur le métis au Brésil. In: Premier Congrès Universel des Races: 26-29 juillet 1911. Paris: Devouge, 1911.

NASCIMENTO, A. O Genocídio do Negro Brasileiro: processo de um racismo mascarado. 3. ed. São Paulo: Perspectivas, 2016.

QUEIROZ, Z. C. L. S.; MIRANDA, G. J.; TAVARES, M.; FREITAS, S. C. A lei de cotas na perspectiva do desempenho acadêmico na Universidade Federal de Uberlândia. Revista Brasileira de Estudos Pedagógicos, Brasília, v. 96, n. 243, p. 299-320, 2015.

RAMOS, A. F. C. História e crônica: a Lei dos Sexagenários e as de Machado de Assis (1884-1885). História Social, n. 22-23, p. 61-82, 2012. 
GAIA, R da S.P.; VITÓRIA, A. da S.; PEREIRA, J. A. G.; SCORSOLINI-COMIN, F.

SANTOS, G. A. Nem crime, nem castigo: o racismo na percepção do judiciário e das vítimas de atos de discriminação. Revista do Instituto de Estudos Brasileiros, n. 62, p. 184-207, dez. 2015.

SANTOS, H. Uma teoria para a questão racial do negro brasileiro. A trilha do círculo vicioso. São Paulo em Perspectiva, v. 8, n. 3, p. 56 - 65, 1994.

SILVA, J. M. Raízes do Conservadorismo Brasileiro: a abolição na imprensa e no imaginário social. 3. ed. Rio de Janeiro: Civilização Brasileira, 2018. 448p.

SOUSA, P. J. S. Lei n. 1 de 1837, e decreto n. 15 de 1839, sobre instrução primária no Rio de Janeiro. Revista História da Educação, Pelotas, n. 18, p. 199-205, jul./dez. 2005.

TORRES, Á. L. P. Ações Afirmativas e Limites às Políticas Públicas de Igualdade. 2012. 130 f. Dissertação (Mestrado em Direito). Universidade Metodista de Piracicaba, Piracicaba, 2012.

Enviado em: 11/03/2020

Aprovado em: 07/04/2021

Publicado em: 15/06/2021 